Pediat. Res. 14: 779 (1980)

\title{
Letter to the Editor: Lysine Intolerance in Methylmalonic Acidemia
}

\author{
ICHIRO MATSUDA, ${ }^{(12)}$ NORIYUKI NAGATA. ITSUKO UEHARA, AND TAKENORI TERASHIMA
}

Department of Pediatrics, Kumamoto University Hospital, 860 Kumamoto, Japan

There are two different metabolic pathways to synthesize urea: (a) Krebs-Henselite urea cycle; and (b) lysine-homocitrullinehomoarigine-urea cycle, although the latter is a minor pathway and supported by a few reports $(5,7,8,10)$. The first two steps of Krebs-Henselite cycle-carbamylphosphate synthesis and conversion from ornithine to citrulline are located at mitochondria in the liver, where a step of lysine to homocitrulline is also thought to be located (2).

The connections of hyperlysinemia and hyperammonemia in urea cycle disorders was reported in ornithine carbamyltransferase deficiency (4), citrullinemia $(5,8)$, hyperlysinemia (1), and hyperornithinemia (2). In methylmalonic acidemia, hyperlysinemia and hyperammonemia were also noted $(6,9)$. In earlier report, we used the lysine loading test in two patients with variant form of citrullinemia, in whom a higher elevation was found in blood lysine, ammonia, and urinary lysine as well as in urinary homocitrulline and homoarginine (5). These observations prompt us to perform the same loading test in a patient with methylmalonic acidemia. A patient diagnosed as having methylmalonyl CoA mutase deficiency in cultured lymphocytes and skin fibroblasts (5) was receiving lysine $(100 \mathrm{mg} / \mathrm{dl}$ per os) at attack of the episode and under dietary control, where blood methylmalonic acid was 250 and below $10 \mu \mathrm{g} / \mathrm{ml}$, respectively. In the former condition, serum lysine was elevated from 3.5 to $38.8 \mu \mathrm{mol} / \mathrm{dl}$, blood ammonia was elevated from 184 to $290 \mu \mathrm{g} / \mathrm{dl}$, and urine lysine was elevated from 113 to $986 \mathrm{~mole} / \mathrm{g}$ creatinine [these increments were higher than those in control in our laboratory (6)], but no elevation was found in urinary homocitrulline and homoarginine. On the contrary, in the latter condition, serum lysine $(5.1 \mu \mathrm{mole} / \mathrm{dl})$ and blood ammonia $(111 \mu \mathrm{g} / \mathrm{dl})$ were essentially unchanged, and an increase in urine lysine from 120 to $540 \mathrm{~mole} / \mathrm{g}$ creatine was within control range.

Loading test was repeated using a double amount of lysine at another attack of episode; urinary homocitrulline and homoargine were again not elevated.

Shapiro et al. (9) found decreased activities of all 5 enzymes in Krebs-Henselite urea cycle in an autopsied liver sample of methylmalonic acidemia. In rat and human liver homogenate, methylmalonyl CoA but not methylmalonic acid inhibited carbamylphosphate synthetase $1(3)$.

Copyright (1) 1980 International Pediatric Research Foundation. Inc. $0031-3998 / 80 / 1405-0779 \$ 02.00 / 0$
If lysine-urea cycle is intact in our patient, urinary homocitrulline and homoarginine might be elevated as blood ammonia increased, like in citrullinemia $(6,8)$ and other Krebs-Henselite urea cycle disorders (4). Observed results may suggest that elevated blood methylmalonic acid or methymalonyl CoA has a toxic effect on lysine and ammonia metabolism, possibly on the stage of mitochondrial function.

\section{REFERENCES AND NOTES}

1. Colombo J. P. Pidrterich. R., Donath. A., Spahr. A., and Rossi, E: Congenital lysine intolerance with periodic ammonia intoxication. Lancet, $I: 1014$ (1964). 2. Fell, V.. Pollitt. R. J., Sampson, G. A., and Wright, T.: Ornithinemia, hyperammonemia and homocitrullinuria. Am. J. Dis. Child., 127: 752 (1974).

Gruskay, J. A and Rosenberg. L. E.: Inhibition of hepatic mitochondrial carbamyl phosphatase synthetase (CPS \pm ) by acyl CoA esterase: possible mechanism of hyperammonemia in the organic acidemias. Pediatr. Res. (Abmechanism of hyperam

4. Krieger, I., Bachman, C., Gronemeyer, W., and Cejku, J.: Propionic acidemia and hyperlysinemia in a case with ornithine transcarbamylase (OCT) deficiency. J. Clin. Endocrinol. Metab., 43: 796 (1976).

5. Matsuda. I., Arashima, S.. Imanishi, Y.. Yamamoto. J., Akaboshi, I., Shinozuka. S.. and Nagata, N.: Lysine intolerance in a variant form of citrullinemia. Pediatr. Res.. 13: 1134 (1979).

6. Matsuda, I., Terashima, T., Yamamoto, J., Akaboshi. I., Shinozuka. S., Hattori. S. Nagata, N and Oka, Y.: Methylmalonic acidemia. Eur. J. Pediatr.. I28 $181(1978)$

7. Ryan, W. L.. Bark, A. J., and Johnson, R. J.: Lysine, homocitrulline and homoarginine metabolism by the isolated perfused rat liver. Arch. Biochem. Biophys., 123: 294 (1968).

8. Scott-Emuakpor, A., Higgis, J. V., and Kohrman. A. F.: Citrullinemia: a new case, with implications concerning adaptation to defective urea synthesis. Pediatr. Res.. 6: 626 (1972).

9. Shapiro, L. J.. Bocan. M. E., Paijman. L., Cedervaum. S. D., and Shaw, K. N. F. Methylmalonyl Co-A mutase deficiency associated with severe neonatal hyperammonemia; activity of urea cycle enzymes. J. Pediatr., 93: 986 (1978).

10. Sogawa, H., Oyanagi. K.., and Nakao, T.: Periodic hyperammonemia, hyperlysinemia and homocitrullinemia associated with decreased argiminosuccinate synthetase and arginianse activities. Pediatr. Res., 11: 949 (1979).

11. This research was supported by a grant for scientific research from the Ministry of Education, Science, and Culture of Japan.

12. Requests for reprints should be addressed to: Ichiro Matsuda, Department of Pediatrics. Kumamoto University Hospital, 860 Kumamoto. Japan.

13. Received for publication January 3, 1980

14. Accepted for publication January 7, 1980. 